\title{
The use of HaloTag-based technology in flow and laser scanning cytometry analysis of live and fixed cells
}

\author{
Elena I Kovalenko ${ }^{1,2}$, Shahin Ranjbar', Luke D Jasenosky ${ }^{1}$, Anne E Goldfeld', Ivan A Vorobjev ${ }^{3,4}$ and \\ Natasha S Barteneva ${ }^{1,5^{*}}$
}

\begin{abstract}
Background: Combining the technologies of protein tag labeling and optical microscopy allows sensitive analysis of protein function in cells.

Findings: Here, we describe development of applications using protein tag technology (HaloTag (HT)-based) for flow and laser scanning cytometry (LSC). Cell lines, expressing recombinant surface $\beta 1$-integrin-HT and HT-p65 fusion protein, and a CD4 T cell line (Jurkat) infected with human immunodeficiency virus type 1 (HIV-1) reporter virus expressing the unfused HT (HIV-1 Lai-Halo $_{\text {, }}$, were stained with different $H T$ ligands and successfully detected by flow cytometers equipped with 488 and $561 \mathrm{~nm}$ lasers as well as a laser scanning cytometer (equipped with 488 and $405 \mathrm{~nm}$ lasers) alone or combined with cell cycle and viability markers.

Conclusions: Use of HT technology for cytometric applications has advantages over its use in microscopy as it allows for the statistical measurement of protein expression levels in individual cells within a heterogeneous cell population in combination with cell cycle analysis. Another advantage is the ability of the HaloTag to withstand long fixation and high concentration of fixative, which can be useful in research of infectious agents like HIV and/ or mycobacteria.
\end{abstract}

\section{Findings}

One limitation of the fluorescent proteins commonly used in the generation of fusion proteins is that new constructs must be created if different colors are required for analysis. In addition to the labor involved, changing the fusion partner can result in dysregulated localization and/or affect the activity of the protein being analyzed [1]. Another problem is that fluorescent proteins are often prone to fixation, making difficult to combine flow cytometric analysis with cell cycle studies or research of infection agents like HIV or mycobacteria which requiring high percentage of fixation and long fixative time. An alternative approach is to use a fusion partner like HaloTag, SNAP-Tag, FIAsH, or others [2-5] that can be "tagged" later with an exogenous fluorescent ligand. Labeling of these protein tags with small

\footnotetext{
* Correspondence: barteneva@idi.harvard.edu

${ }^{1}$ Immune Disease Institute and Program in Cellular and Molecular Medicine, Children's Hospital Boston and Harvard Medical School, Boston, MA, USA Full list of author information is available at the end of the article
}

synthetic ligands depends on the formation of stable complexes between biarsenical compounds and peptides containing a tetracysteine thiol motif [6], and is adaptable to a wide range of cell types [7]. The "tag" technologies have been utilized in diverse experimental procedures, but mainly for in vitro and in vivo imaging of cells with microscopy and immunocytochemistry $[4,7,8]$.

Here we describe the successful application of flow cytometry and laser scanning cytometry (LSC) to cells expressing HT constructs. The HT protein is an engineered monomeric haloalcane dehalogenase from Rhodococcus rhodochrous capable of covalent binding to ligands of interest. The HT ligands harbor reactive linkers that covalently bind to the HT protein and fluorescent reporter groups or affinity handles such as biotin, Oregon Green, tetramethylrhodamine (TMR) and others.

We illustrate the utility of this approach with several different systems: i) surface staining of a U2OS human

\section{() Biomed Central}


osteosarcoma cell line that is stably transfected with a vector encoding $\beta 1$-integrin-HaloTag7 (U2OS- $\beta 1$ IntHT7); ii) intracellular staining of Jurkat CD4 T cells infected with an HIV-1 reporter virus (HIV-1 $1_{\text {Lai-Halo }}$ ) that encodes an unfused HT; and iii) intracellular staining of a HEK-293 cell line that expresses a HT fusion with the nuclear factor $(\mathrm{NF} \kappa \mathrm{B})$ p 65 subunit. The $\beta 1$ IntHT7 construct is well expressed and tolerated in multiple mammalian cell types [9].

We first took advantage of the statistical possibilities associated with laser scanning cytometry of adherent cells. U2OS- $\beta 1$ Int-HT7 cells were seeded at a density of $0.5 \times 10^{6}$ cells $/ \mathrm{ml}$ in a 96 -well flat-bottom plate in a volume of $100 \mu \mathrm{l} /$ well and were grown overnight in DMEM supplemented with $10 \%$ fetal bovine serum (FBS), $2 \mathrm{mM} L$-glutamine, $10 \mathrm{mM}$ HEPES, $100 \mathrm{U} / \mathrm{ml}$ penicillin, $100 \mu \mathrm{g} / \mathrm{ml}$ streptomycin (all from Gibco products, Invitrogen, Carlsbad, CA), in a humid atmosphere of $5 \% \mathrm{CO}_{2}$ at $37^{\circ} \mathrm{C}$. Cells were treated with methyl jasmonate (MJ) (1 or $0.5 \mathrm{mM})$, staurosporine (STS) (0.5 or $0.25 \mu \mathrm{g} / \mathrm{ml}$ ) (both Sigma, St-Louis, MO), or left untreated for $16 \mathrm{~h}$, and then washed with warm medium. The cells were then stained with Oregon Green $(0.5 \mu \mathrm{M})$ or Alexa $488(1.0 \mu \mathrm{M})$ HT ligands (both - Promega, Madison, WI) for $30 \mathrm{~min}$ and carefully washed with warm medium; Hoechst $33342(5 \mu \mathrm{g} / \mathrm{ml})$, and propidium iodide (PI) $(1 \mu \mathrm{g} / \mathrm{ml})$ were added for $30 \mathrm{~min}$ before analysis. Fluorescence was excited with the 488 and $405 \mathrm{~nm}$ lasers. The intensities of maximal pixel and integrated fluorescence were quantified and recorded for each cell. At least 3,000 cells were measured per well. Surface $\beta 1$-integrin expression was easily detected using both Oregon Green and Alexa 488 HT ligand staining (Figure 1A). Cellular green (HT ligand Oregon Green), far red (PI), and blue (Hoechst) fluorescence emissions were measured simultaneously in the same cells in situ utilizing standard filter settings and an iCys cytometer (Compucyte, Westwood, MA) (Figure 1C). Mean fluorescence intensity (MFI) of $\beta 1$-integrin expression was calculated per thousand cells in the 96-well plate in a high-throughput manner (Figure 1B) and correlated with the level of apoptosis (pre-G1-peak). $\beta 1$-integrin expression was reduced in a concentration-dependent manner upon addition of $\mathrm{MJ}(1$ and $0.5 \mathrm{mM})$, but not STS $(0.25$ and $0.5 \mu \mathrm{g})$ (Figure 1B). U2OS cells transfected with $\beta 1$-integrin appeared to be much more resistant to apoptosis induced by STS $(0.5 \mu \mathrm{g} / \mathrm{ml}$ ) (data not shown). LSC analysis of U2OS- $\beta 1$ Int-HT7 cells enabled pre-G1 peak quantitation, cell viability, and fluorescent intensity of $\beta 1$-integrin expression to be measured simultaneously (Figure $1 \mathrm{D}, \mathrm{E}$, and 1F).

We next tested the utility of HT system for intracellular flow cytometry. An HIV-1 infectious molecular clone encoding the HT was constructed by introducing the
HT protein (unfused to any other protein sequence) derived from the plasmid pHT2 (Promega, Madison, WI, USA) into the HIV-1 $1_{\text {Lai }}$ (NIH AIDS Research \& Reference Reagent Program) background. This new infectious molecular clone was designated HIV- $1_{\text {Lai-Halo }}$ and was constructed in a manner similar to an EGFP reporter virus described previously [10]. Jurkat $\mathrm{T}$ cells were cultured in RPMI 1640 medium with $2 \mathrm{mM} \mathrm{L-glu-}$ tamine (BioWhittaker, Inc., Walkersville, MD) supplemented with $10 \%$ heat inactivated FBS. Cells $\left(0.5 \times 10^{5}\right.$ cells $/ \mathrm{ml})$ were infected with $\mathrm{HIV}-1_{\text {Lai-Halo }}\left(1000 \mathrm{TCID}_{50}\right)$ and incubated at $37^{\circ} \mathrm{C}$ and $5 \% \mathrm{CO}_{2}$ for 5 days, after which the cultures were terminated. Infected and uninfected (control) cells were labeled with HaloTag TMR (5 $\mu \mathrm{M})$ or HaloTag Oregon Green $(1 \mu \mathrm{M})$ ligand in medium for $40 \mathrm{~min}$ at $37^{\circ} \mathrm{C}$ and then washed three times with phosphate buffered saline (PBS). Cells were further incubated with fresh medium for $40 \mathrm{~min}$ at $37^{\circ} \mathrm{C}$ before they were washed with PBS (three times) and fixed with $4 \%$ paraformaldehyde (PFA) plus $0.2 \mathrm{M}$ sucrose in PBS for $2 \mathrm{~h}$ before analysis. Cells were analyzed using a FACSAria cytometer (BD Biosciences, San Jose CA) equipped with $488 \mathrm{~nm}$ and/or $561 \mathrm{~nm}$ lasers. Virusderived HT protein was easily detected after staining with Oregon Green (Figure 2A and 2D) or TMR (Figure 2B). Fixation of cells with $4 \%$ PFA for $2 \mathrm{~h}$ had little effect on fluorescence intensity of the infected cells stained with TMR HT ligand (Figure 2C) and no effect on Oregon Green HT ligand (data not shown).

We also performed intracellular staining of the HEK293 cell line stably expressing HT-p65 fusion protein. Cells were fixed with $1 \%$ PFA for $1 \mathrm{~h}$ at $4^{\circ} \mathrm{C}$ following a 30-min permeabilization at $4{ }^{\circ} \mathrm{C}$ with $70 \%$ ethanol and staining with the Alexa $488 \mathrm{HT}$ ligand $\left(30 \mathrm{~min} \times 37^{\circ} \mathrm{C}\right.$ w/o fixation for Oregon Green). As shown in Figures $2 \mathrm{E}$ and $2 \mathrm{~F}$, ligand concentration can be optimized in order to achieve a good signal-noise ratio.

Analysis of HT expression using cytometers equipped with green-yellow lasers (laser excitation $561 \mathrm{~nm}$ ) and green lasers $(534 \mathrm{~nm})$ enables the use of a versatile set of ligands, including TMR $\left(494_{\mathrm{Ex}} / 516_{\mathrm{Em}}\right)$ or HT-DiAcFAM ligand $\left(494_{\mathrm{Ex}} / 526_{\mathrm{Em}}\right)$. Before introduction of green-yellow and green lasers in the standard cytometer optical configuration, the availability of HT ligands for cytometry applications was limited by HT ligands excited with the $488 \mathrm{~nm}$ laser (Oregon Green and Alexa 488 ) and biotin-conjugated ligands. However, because biotin is an essential co-factor in the cytosol and in mitochondria, the use of biotin-conjugated ligands may result in a significant level of nonspecific binding, especially in intracellular applications.

The use of interchangeable ligands that recognize the HT and emit in green and red ranges makes it possible to modify a particular experiment in order to (1) avoid 


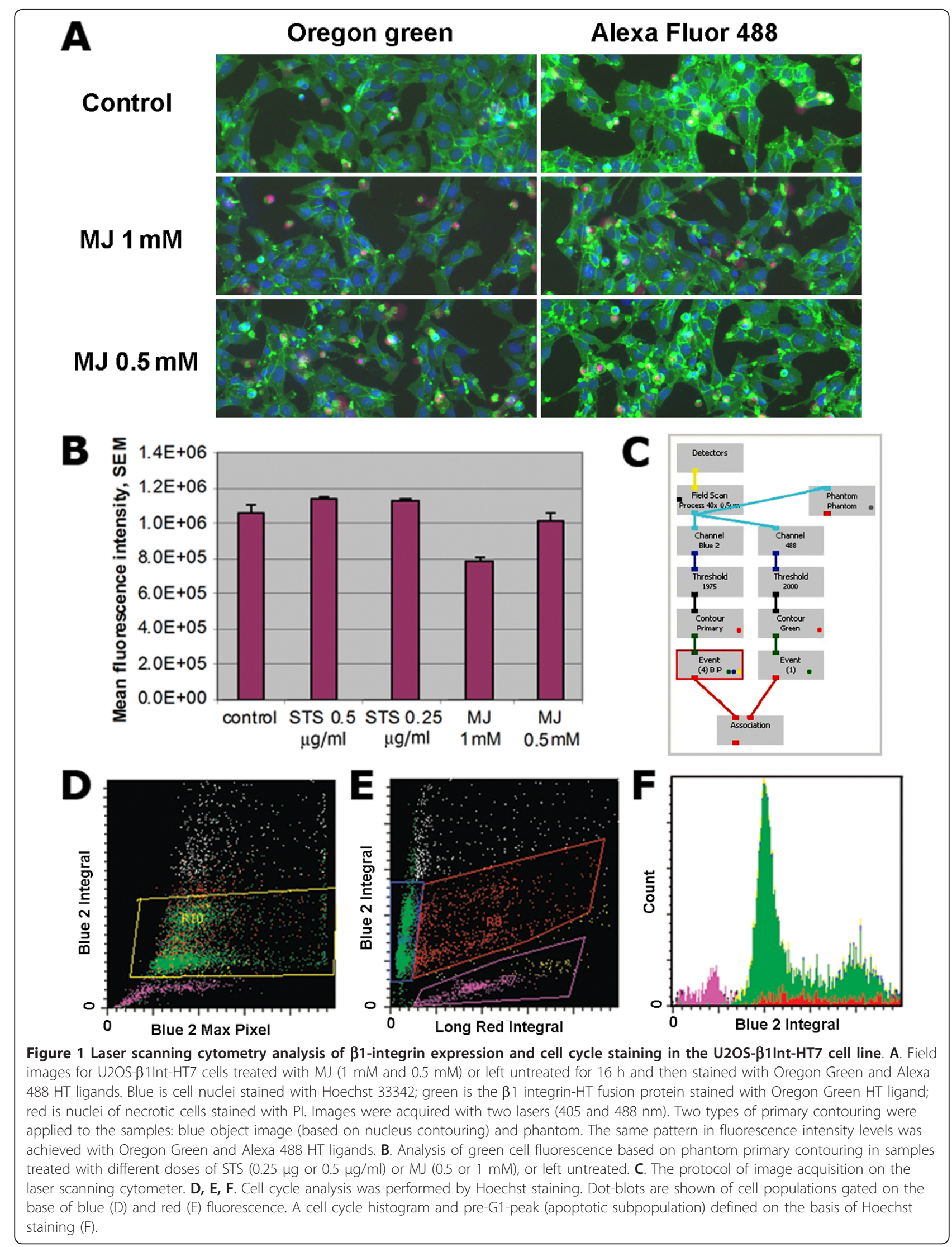




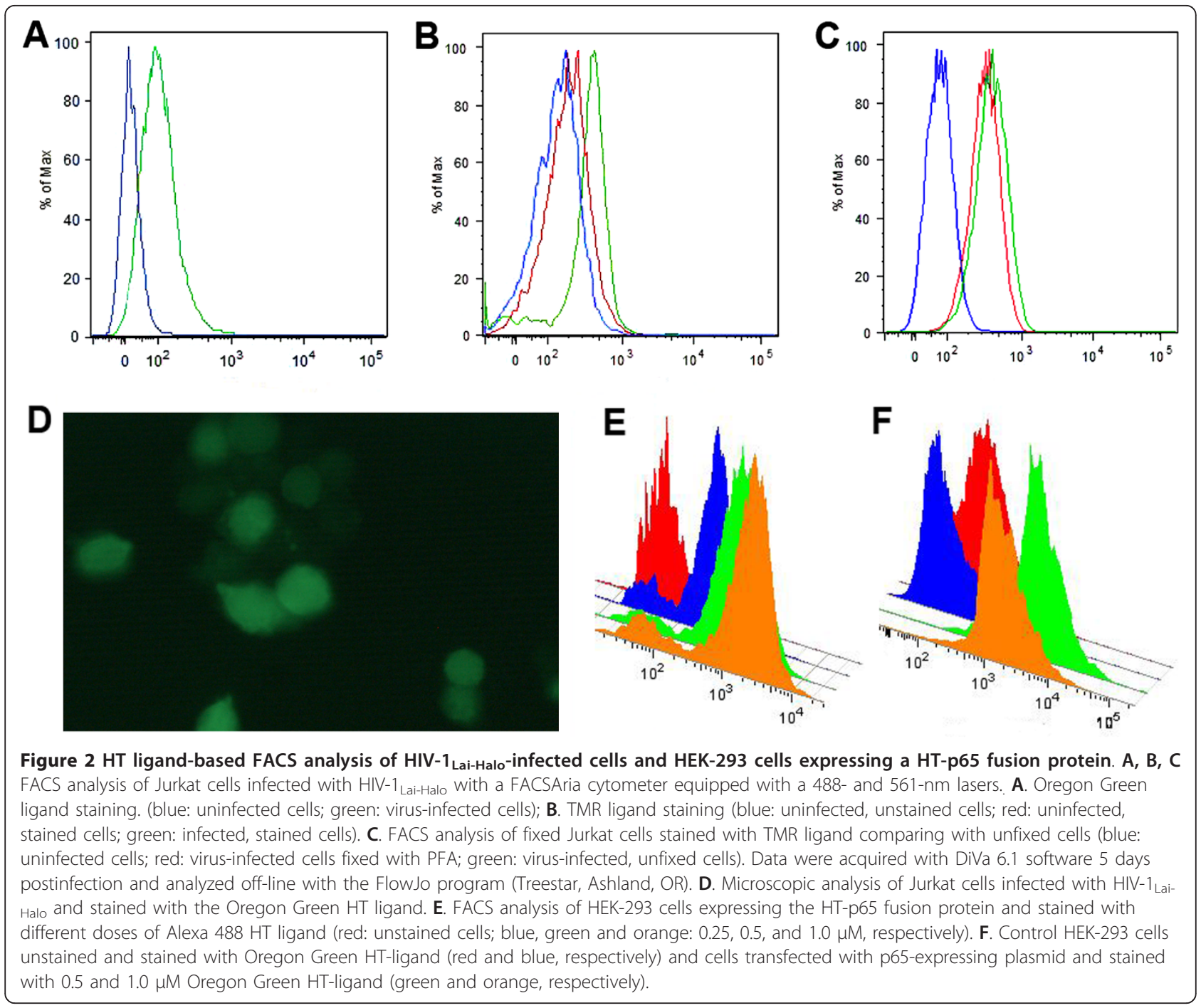

undesirable spectral overlapping; (2) decrease autofluorescence with TMR or other red-emitting HT ligands; (3) manipulate colors interchangeably for surface or intracellular staining without the need to generate additional plasmids encoding new fusion partner combinations; and (4) perform extensive cell fixation if infectious agents that require inactivation like HIV or Mycobacterium tuberculosis are being studied. The cytometric approach described herein should be applicable to other "tagged" proteins that utilize a diverse selection of fluorescent ligands (SNAP-tag, etc.) and to a wide range of host cells. In addition, since the HT ligand is connected by a stable covalent bond to its target protein, the fluorescently labeled HT fusion protein can be characterized by SDS-PAGE without loss of fluorescent signal (4).

The combination of HT technology with flow and imaging cytometry analysis has major advantages over microscopy-based methods. As shown here, these cytometric methods allow investigators to statistically assess the expression level of multiple proteins in individual cells within a heterogeneous cell population, and can be combined with cell cycle analysis, viability evaluation, and cell surface/intracellular staining, although nonspecific binding of HT ligands to untagged cellular components remains an issue. Taken together, the newly implemented applications for HT technology described herein should promote the adoption of rapid, efficient and quantitative multiplexing of "tagged" proteins with cell cycle dyes and fluorochrome-conjugated antibodies.

List of abbreviations used

B1-integrin-HT7: vector encoding $\beta 1$-integrin-HaloTag7; DiAcFAM: diacetyl derivative of fluorescein; EGFP: enhanced green fluorescent protein; FBS: fetal bovine serum; FIAsH: fluorescein arsenical hairpin; HIV: human immunodeficiency virus; HIV-1 $1_{\text {Lai-Halo: }}$ human immunodeficiency virus type 1 (HIV-1) reporter virus expressing the unfused HT; HT: Halotag; LSC - laser 
scanning cytometry; MFI: mean fluorescent intensity; MJ: methyl jasmonate; PBS: phosphate buffered saline; PFA: paraformaldehyde; PI: propidium iodide; SDS-PAGE: SDS-polyacrylamide gel electrophoresis; SNAP-tag: is a $20 \mathrm{kDa}$ mutant of the human DNA repair protein O6-alkylguanine-DNA

alkyltransferase (hAGT) that reacts specifically and rapidly with benzylguanine and benzylchlopyrimidine derivatives carrying a variety of different synthetic fluorophores; STS: staurosporine; TMR: tetramethylrhodamine.

\section{Acknowledgements}

Funding was provided in part by $\mathrm{NIH}$ and the Immune Disease Institute to N.B. and A.G. We are grateful to Dr. Georgiy Los and Natasha Karassina for providing the U2OS cell line expressing the HT- $\beta 1$ integrin fusion protein and the HEK-293 cell line expressing the HT-p65 fusion protein. We also thank Dr. Elena Holden and Ed Luther for access to the laser scanning cytometric instrumentation.

\section{Author details}

${ }^{1}$ Immune Disease Institute and Program in Cellular and Molecular Medicine, Children's Hospital Boston and Harvard Medical School, Boston, MA, USA. ${ }^{2}$ Shemyakin-Ovchinnikov Institute of Bioorganic Chemistry, Russian Academy of Sciences, Moscow, Russia. ${ }^{3}$ National Hematological Scientific Center, Moscow, Russia. ${ }^{4}$ Belozersky Institute of Physico-Chemical Biology, Moscow State University, Moscow, Russia. ${ }^{5}$ Department of Pediatrics, Harvard Medical School, Boston, MA, USA.

\section{Authors' contributions}

EK and SR designed the research, performed the experiments, analyzed the results and drafted the paper. LDJ created HIV-1 $1_{\text {Lai-Halo }}$ construct and contributed in data interpretation and report writing. AEG supervised SR and LDJ, coordinated the research, provided funding. IAV contributed in design of research, data interpretation and commented on manuscript. NSB designed and coordinated research, analyzed the data, wrote the manuscript and provided funding. All authors read and approved the final manuscript.

\section{Competing interests}

The authors declare that they have no competing interests.

Received: 11 June 2011 Accepted: 9 September 2011

Published: 9 September 2011

\section{References}

1. Lisenbee CS, Karnik SK, Trelease RN: Overexpression and mislocalisation of a tail-anchored GFP redefines the identity of peroxisomal ER. Traffic 2003, 4:491-501.

2. Keppler A, Kindermann M, Gendreizig S, Pick H, Vogel H, Johnson K: Labeling of fusion proteins of O6-alkylguanine-DNA alkyltransferase with small molecules in vivo and in vitro. Methods 2004, 32:437-444.

3. Tirat A, Freuler F, Stettler T, Mayr LM, Leder L: Evaluation of two novel tagbased labeling technologies for site-specific modification of proteins. Inter I Biolog Macromolecules 2006, 39:66-76.

4. Los GV, Wood K: The HaloTag: a novel technology for cell imaging and protein analysis. Methods Mol Biol 2007, 356:195-208.

5. Gautier A, Juillerat A, Heinis C, Correa IR, Kindermann M, Beaufils F, Johnsson $\mathrm{K}$ : An engineered protein tag for multiprotein labeling in living cells. Chem Biol 2008, 15:128-136.

6. Griffin BA, Adams SR, Tsien RY: Specific covalent labeling of recombinant protein molecules inside live cells. Science 1998, 281:269-272.

7. Lang C, Schulze J, Mendel RR, Hansch R: HaloTag: a new versatile reporter gene system in plants. J Experiment Botany 2006, 57:2985-2992.

8. Schroeder J, Benink H, Dyba M, Los GV: In vivo labeling method using a genetic construct for nanoscale resolution microscopy. Biophysical J 2008, 96:L01-3.

9. Svendsen S, McMillan E, Zimprich C, Swendsen CN, Los GV: HaloTag protein: a novel reporter protein for human neural stem cells. Promega Notes 2007, 95:20-22.

10. Brown A, Gartner S, Kawano T, Benoit N, Cheng-Mayer C: HLA-A2 downregulation on primary human macrophages infected with an M-tropic EGFP-tagged HIV-1 reporter virus. J Leukoc Biol 2005, 78:675-685.

\section{doi:10.1186/1756-0500-4-340}

Cite this article as: Kovalenko et al:: The use of HaloTag-based technology in flow and laser scanning cytometry analysis of live and fixed cells. BMC Research Notes 2011 4:340.

\section{Submit your next manuscript to BioMed Central and take full advantage of:}

- Convenient online submission

- Thorough peer review

- No space constraints or color figure charges

- Immediate publication on acceptance

- Inclusion in PubMed, CAS, Scopus and Google Scholar

- Research which is freely available for redistribution

Submit your manuscript at www.biomedcentral.com/submit
Biomed Central 